\title{
PENETAPAN GANTI RUGI BAGI PELBAGAI KECEDERAAN DIRI MENURUT PERUNDANGAN ISLAM
}

\section{Determination of Compensation for Various Personal Injuries in Islamic Law}

\author{
Shahidra Abdul Khalil * \\ Syed Mohd Jeffri Syed Jaafar ** \\ Abdul Karim Ali ***
}

\begin{abstract}
Implementation of Islamic criminal laws in modern days, in multi-ethnic and multi-religious country is a challenging issue. This is due to negative perception against the law especially hudud law which is perceived as harsh and irrelevant in modern days. However, the aspiration to implement Islamic criminal laws may be feasible if it is begun with the implementation of diyat. Generally, diat is a compensation for fatality and personal injury with the fixed rates determined by Shariah. Compared to hudud and qisas, the implementation of diyat may be less controversial as the main objective is to protect the victim and the heirs' right with financial liability
\end{abstract}

\footnotetext{
* Senior Lecturer, Department of Fiqh and Usul, Academy of Islamic Studies, University of Malaya, shahidra@um.edu.my

** Senior Lecturer, Department of Fiqh and Usul, Academy of Islamic Studies, University of Malaya, syedjeffri89@um.edu.my

*** Assoc Professor, Department of Fiqh and Usul, Academy of Islamic Studies, University of Malaya, abdkarim@um.edu.my
} 
charged to the wrongdoer. From previous literatures, it is found that discussions on implementation of diat is scarce and mainly focus on basic theory of diat without further discussion on the determination methodology of the rates for more complex injuries. Hence, this article aims to fill the loopholes by discussing the methodology in determining the diyat rates for various injuries. The application of the methodologies namely al-ta' addud, al-tadākhul and determination of rates based on ratio as discussed by the Islamic scholars is analysed. The article reveals that al-ta'addud methodology applies when injuries occur in different part of body. Whereas, al-tadākhul applies when several injuries overlap in same or related part of body and compensation is proportioned to the full amount of diyat if the loss of body part or its function is partial. For complex injuries, referral to expert and utility of current medical technologies in determining the type and severity of the injuries is advocated. In conclusion, all the methodologies for determining diyat rates are relevant as it can be applied in current context for various types of injury.

Keywords: Personal Injury, Compensation, Diat, Arsh, alTadākhul

\section{PENDAHULUAN}

Kewajipan memberikan ganti dalam syariat Islam timbul apabila berlaku kerosakan pada harta dan manfaat harta individu atau atas kemudaratan yang dilakukan ke atas dirinya akibat perbuatan salah. ${ }^{1}$ Namun, liabiliti ini tertakluk kepada beberapa syarat iaitu

Muhammad al-Zuhaylī, Naẓariyyat al-Damān aw Ahkām alMas'üliyyah al-Madaniyyah wa al-Jinā'iyyah fì al-Fiqh al-Islämī Dirāsah Muqāranah (Damsyik: Dār al-Fikr, 1998), 15. 
kerosakan benar-benar berlaku, ${ }^{2}$ ia meninggalkan kesan fizikal ${ }^{3}$ dan kerosakan itu kekal. ${ }^{4}$ Kematian dan kecederaan anggota tubuh diperuntukkan dengan diat, arsh dan hukūmah al-'adl. Namun, ganti rugi ini diperuntukkan kepada mangsa jika pelaku salah menghilangkan nyawa atau mencederakan tanpa niat atau tidak sengaja. ${ }^{5}$ Jika perbuatan dilakukan dengan sengaja, hukuman yang diperuntukkan ke atas pelaku adalah qisas atau perbuatan balas yang menjadi hak mangsa atau walinya. Pengecualian kepada pembayaran diat atau ganti rugi hanya berlaku dalam kes sengaja jika mangsa memaafkan pelaku atau qisas tidak dapat dilaksanakan atas sebab-sebab yang dibenarkan syarak.

Diat, arsh dan hukūmah al-'adl secara umum merupakan bayaran yang perlu dijelaskan kepada mangsa atau walinya akibat kehilangan nyawa dan kecederaan tubuh badan yang berlaku secara salah. Istilah-istilah tersebut membawa maksud yang berbeza seperti perbincangan berikutnya. Pertama, kadar bayaran, sama ada diperuntukkan secara tetap atau tidak. Diat dan arsh adalah ganti rugi yang ditetapkan kadarnya, ${ }^{6}$ manakala hukümah al- 'adl pula diserahkan penilaiannya kepada pemerintah. ${ }^{7}$ Perbezaan kedua adalah bentuk musibah yang mewajibkan ganti rugi-ganti rugi tersebut. Diat diperuntukkan bagi kehilangan dan kecederaan anggota sepenuhnya manakala arsh dan hukūmah al-'adl pula diperuntukkan bagi kecederaan dan kehilangan sebahagian

2 Al-Zuhaylī, Nazariyyat al-Ḍamān, 96; 'Alī al-Khafîf, al-Damān fì al-Fiqh al-Islāmī (Kaherah: Dār al-Fikr al-'Arabī, 2000), 38.

3 Muḥsin 'Abd Farḥān Șāliḥ al-Jumaylī, al-Gharāmah al-Māliyyah fì al-Hudūd wa al-Jināyat 'alā al-Nafs al-Bashariyyah wa mā Dūnihā fì al-Fiqh al-Islāmī (Beirut: Dār al-Kutub al-'Ilmiyyah, 2006), 29.

4 Al-Zuhaylī, Nazariyyat al-Damān, 60; Hamād bin Muḥammad alJābir al-Hajīiñ, al-Qawā'id wa al-Dawābit al-Fiqhiyyah fì al-Damān al-Māli (Riyad: Dār Kunūz Ishbiliyya li al-Nashr wa al-Tawzī‘, 2008), 88; Husnā 'Abd al-Sam̄̄' Ibrāhim, Mawqīf al-Fuqahā' min Damān al-Amwāl fì al-Sharī 'ah al-Islāmiyyah Dirāsah Muqāranah (Dimyat: Maktabah Nanasi, 2004), 45.

5 Seperti mana yang dinyatakan dalam surah al-Nisā' (4): ayat 92.

6 Muhammad Aḥmad Sarāj, Damān al-'Udwān fì al-Fiqh al-Islāmī Dirāsah Fiqhiyyah Muqāranah bi Ahkēm al-Mas'ūliyyah alTaqșiriyyah fì al-Qānūn (Kaherah: Dār al-Thaqāfah li al-Nashr wa al-Tawzī', 1990) 439.

7 Muḥammad Aḥmad Sarāj, Damān al- 'Udwān. 
daripadanya. Bezanya, bentuk kecederaan yang mewajibkan arsh diperuntukkan dengan kadar tertentu. Hukümah al- 'adl pula tidak ditentukan kadarnya, justeru disebut juga sebagai arsh yang tidak ditentukan (arsh ghayr muqaddar). ${ }^{8}$

Terdapat juga beberapa istilah lain yang seringkali merujuk kepada pembayaran ganti rugi terhadap kehilangan manfaat sesuatu atau berlaku kerosakan pada sesuatu seperti al-damān. Walau bagaimanapun al-ḍamān membawa maksud ganti rugi bagi kerosakan harta benda dan kerugian material yang dialami oleh seseorang. Ia hanya diperuntukkan bagi harta yang bernilai sahaja sama ada harta alih atau harta tidak alih. ${ }^{9}$ Justeru, makalah ini memfokuskan mengenai penetapan ganti rugi yang telah ditetapkan kadarnya oleh syarak bagi kecederaan diri iaitu diat dan arsh. Ini kerana para hakim tiada kuasa yang luas dalam menetapkan kadarnya melainkan berdasarkan apa yang telah ditentukan. Namun, disebabkan tidak semua bentuk kecederaan diperincikan kadarnya melalui al-Quran mahupun hadis, panduan yang boleh difahami daripada kedua sumber perundangan ini perlu diteliti bagi memandu para hakim dalam membuat penetapan kadar yang selari dengan tuntutan syariat.

\section{GANTI RUGI BAGI KECEDERAAN DIRI DALAM PERUNDANGAN ISLAM}

Obligasi pembayaran diat bagi kesalahan menghilangkan nyawa secara tidak sengaja, diperuntukkan melalui al-Quran iaitu pada ayat 92 surah al-Nisā' seperti berikut:

Terjemahan: Dan tidak harus sama sekali bagi seseorang mukmin membunuh seorang mukmin yang lain, kecuali dengan tidak sengaja. Dan sesiapa yang membunuh seorang mukmin dengan tidak sengaja, maka (wajiblah ia membayar kafarah) dengan memerdekakan seorang hamba yang beriman serta membayar diat (denda ganti nyawa) yang diserahkan kepada ahlinya (keluarga simati), kecuali jika mereka sedekahkan kepada ahlinya (memaafkannya). Tetapi

\footnotetext{
8 Muḥammad Aḥmad Sarāj, Damān al- 'Udwān.

9 Al-Zuhaylī, Naẓariyyat al-Ḍamān, 112.
} 
jika ia (yang terbunuh dengan tidak sengaja) dari kaum (kafir) yang memusuhi kamu, sedang ia sendiri beriman, maka (wajiblah si pembunuh membayar kafarah sahaja dengan) memerdekakan seorang hamba yang beriman. Dan jika ia (orang yang terbunuh dengan tidak sengaja itu) daripada kaum (kafir) yang ada ikatan perjanjian setia antara kamu dengan mereka, maka wajiblah membayar 'diat' (denda ganti nyawa) kepada keluarganya serta memerdekakan seorang hamba yang beriman. Dalam pada itu, sesiapa yang tidak dapat (mencari hamba yang akan dimerdekakannya), maka hendaklah dia berpuasa dua bulan berturut-turut; (hukum yang tersebut) datangnya daripada Allah untuk menerima taubat (membersihkan diri kamu). Dan (ingatlah) Allah Maha Mengetahui, lagi Maha Bijaksana.

Melalui ayat di atas, dinyatakan bahawa pembalasan bagi kesalahan menghilangkan nyawa secara tidak sengaja adalah diat dan kafarah. Namun, ayat ini tidak memperincikan kadar diat yang diwajibkan. Perincian mengenai kadar diat dinyatakan melalui banyak hadith Nabi SAW. Bentuk kecederaan yang diperuntukkan dengan diat dan arsh antaranya dinyatakan dalam hadis berikut:

Daripada 'Amru bin Hazm: Bahawa Rasulullah SAW telah menulis sepucuk surat kepada penduduk Yaman yang di dalamnya ditulis tentang perkaraperkara wajib, sunat dan diat. Maka dibacakan surat itu kepada penduduk Yaman begini tulisannya:

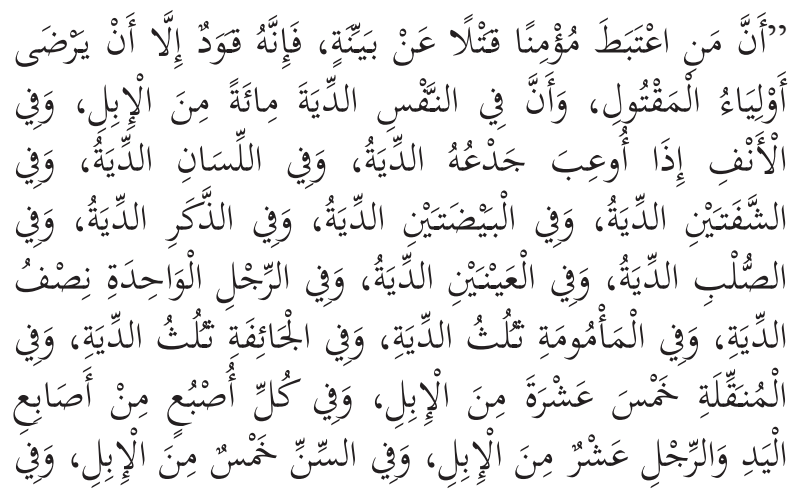




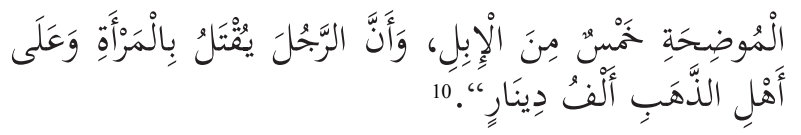

Terjemahan: "Sesungguhnya yang sengaja membunuh seorang Mukmin, maka dikenakan ke atasnya qisas kecuali wali yang terbunuh memaafkannya, dan sesungguhnya pada satu nyawa seratus ekor unta, dan pada hidung jika terpotong satu diat, dan pada lidah satu diat, pada dua bibir satu diat, pada pada dua buah zakar satu diat dan pada zakar satu diat dan pada tulang belakang satu diat, dan pada dua mata satu diyat, dan pada satu kaki setengah diat, dan pada luka sampai ke otak (al-ma'mümah) 1/3 diyat, dan pada luka sampai ke rongga (al-jā'ifah) 1/3 diyat, dan pada luma yang menghancurkan tulang (al-munaqqilah) 15 ekor unta, dan pada setiap jari-jemari tangan dan kaki sepuluh ekor unta, dan pada satu gigi lima ekor unta, dan pada luka yang menampakkan tulang (al-mudihah) lima ekor unta, dan sesungguhnya seorang lelaki itu dibunuh jika dia membunuh seorang wanita dan ke atas ahli emas seribu dinar."

Daripada hadis di atas, dapat difahami bahawa diat diperuntukkan bagi kehilangan nyawa dan kehilangan anggota atau fungsinya secara total, sama ada pada anggota tunggal atau berpasangan. Arsh pula ditetapkan bagi kehilangan satu daripada anggota berpasangan, kecederaan di kepala (shijaj) dan luka pada anggota (jirah). Apa yang jelas melalui hadith di atas juga adalah nilai satu diat ditetapkan sebanyak 100 ekor unta atau 1,000 dinar emas. Namun, selain daripada dua medium ini, para fuqaha menerima empat lagi medium pembayaran diat seperti perak 12,000 dirham, ${ }^{11}$ lembu 200 ekor, kambing 2,000 ekor dan

${ }_{10}$ Sunan al-Nasa $\bar{a}$ '̄ al-Ṣughrā, Kitāb al-Qasāmah, hadith no. 4797.

11 Nilai 12,000 merupakan nilai yang ditetapkan oleh Nabi SAW.

Sunan Ibn Mājah, Kitāb al-Diyāt, hadith no. 2629. 
pakaian 200 pasang. Pembayaran melalui medium-medium ini juga disandarkan kepada Nabi SAW melalui beberapa riwayat. ${ }^{12}$

Dalam realiti semasa, transaksi ekonomi dilakukan menggunakan wang kertas. Unta, emas, perak, lembu, kambing dan pakaian tidak lagi digunakan sebagai medium transaksi kecuali dinar dan dirham di beberapa negara. Justeru, menurut perbincangan para sarjana, pembayaran diat pada zaman ini boleh dibuat menggunakan wang kertas bersandarkan kepada nilai diat yang ditetapkan melalui medium-medium di atas. Pihak pemerintah boleh menetapkan sandaran yang sesuai. ${ }^{13}$

Namun, daripada enam medium pembayaran tersebut, nilai emas dan perak dilihat lebih mudah untuk dinilai dan ditukar

12 Pembayaran diat melalui medium dinar, dirham, lembu dan kambing disandarkan kepada riwayat Amru bin Shu'ayb berikut: "Ketika harga unta meningkat, Baginda pernah mengenakan kepada masyarakat kampung sebanyak empat ratus dinar, manakala dalam keadaan lain pula, mengenakan sehingga lapan ratus dinar ataupun bersamaan dengan lapan ribu dirham. Apabila diat dikenakan ke atas masyarakat yang memiliki lembu, ia hendaklah dibayar dengan dua ratus ekor lembu. Dan bagi masyarakat yang memiliki kambing, maka kadarya ialah dua ribu ekor kambing." Sunan Ibn Mājah, Kitāb al-Diyāt, hadith no. 2630.

Pembayaran diat menggunakan medium pakaian pula, disandarkan kepada arahan khalifah Umar al-Khattab yang diriwayatkan oleh Abu Dawud daripada Amru Ibn Shu'aib daripada bapanya daripada datuknya seperti berikut: "Nilai diat di zaman Nabi SAW ialah 800 dinar atau 8000 dirham, manakala diat ahli kitab pada masa itu ialah separuh diat orang Islam. Katanya: Dan ia berterusan sedemikian sehinggalah Umar menjadi khalifah dan katanya lagi: Ketika harga unta meningkat, maka dinilaikan (unta) oleh Umar bagi orang yang bertransaksi dengan emas sebanyak seribu dinar, yang bertransaksi dengan dua belas ribu dirham, masyarakat yang memiliki lembu dengan dua ratus ekor lembu, masyarakat yang memiliki kambing dengan dua ribu ekor kambing dan masyarakat yang mengusahakan pakaian dengan dua ratus pasang pakaian." Sunan Abī Dāwud, 2: 536.

13 Muḥammad Aḥmad Sarāj, Damān al- 'Udwān, 444. 
dengan mata wang semasa. ${ }^{14}$ Antara dua medium ini pula, para pengkaji cenderung memilih 1,000 dinar yang bersamaan dengan 4250 gram emas 916 sebagai sandaran nilai diat terbaik dalam Ringgit Malaysia. ${ }^{15}$ Ini kerana nilai emas lebih stabil dan meningkat berbanding perak yang mengalami penurunan harga yang ketara. ${ }^{16}$ Walau bagaimanapun, jika harga emas mencecah nilai yang terlalu tinggi, kerajaan boleh juga mempertimbangkan 10,000 dirham ${ }^{17}$ atau 12,000. Pemilihan ini bergantung pada ijtihad pemerintah, sesuai dengan amalan pada zaman Nabi SAW dan khalifah Umar al-Khattab ketika harga unta menjadi terlalu tinggi. Anggaran nilai diat dan arsh bagi kehilangan nyawa dan kecederaan tubuh dalam Ringgit Malaysia semasa (setakat November 2019) yang bersandarkan kepada emas dan perak adalah seperti berikut:

Diat penuh mengikut nilai emas semasa:

1 dinar emas

$=\mathrm{RM} 778.0018$

1000 dinar emas

$=\mathrm{RM} 778,000.00$

Diat penuh mengikut nilai perak semasa:

1 dirham

$=$ RM20.0019

12,000 dirham

$=\mathrm{RM} 240,000.00$

$14 \quad$ Siti Zubaidah Ismail, "Kecuaian dan Ganti rugi terhadap Kecederaan Fizikal Menurut Undang-undang Tort Islam," (Tesis kedoktoran, Akademi Pengajian Islam Universiti Malaya, 2005), 175.

15 Ibid, 184.

16 Ibid.

17 Nilai 10,000 dirham diputuskan oleh khalifah Umar al-Khattab di zaman pemerintahannya.

18 Dinar dan dirham Kelantan menepati syarat sebagai mata wang syariah yang halal menurut syarak berdasarkan piawaian Khalifah Umar Al-Khattab. Piawaian ini menetapkan hubungan dinar-dirham sebagai berat 7 koin 1 dinar bersamaan dengan berat 10 koin 1 dirham. Secara amnya berat 1 dinar ialah $4.25 \mathrm{~g}$ emas berketulenan 22k (91.7\%); manakala 1 koin dirham bersamaan $2.975 \mathrm{~g}$ perak tulen. Portal rasmi Kelantan Golden Trade, capaian pada 1 November 2018, https://kgt.com.my/shop/index.php?route=product/ product\&product_id=58\&search=dinar.

19 Portal rasmi Kelantan Golden Trade, capaian pada 1 November 2018, https://kgt.com.my/shop/index.php?route=product/ search\&search=dirham 
Penetapan Ganti Rugi bagi Pelbagai Kecederaan Diri

Menurut Perundangan Islam

Jadual 1: Nilai Diat Semasa Berdasarkan Nilai Emas dan Perak bagi

Pelbagai Jenis Kehilangan dan Kecederaan Anggota Tubuh

(Setakat November 2019)

\begin{tabular}{|c|c|c|c|c|}
\hline 象 & $\begin{array}{c}\text { Jenis anggota/ } \\
\text { manfaat }\end{array}$ & Kadar diat/arsh & $\begin{array}{c}\text { Nilai } \\
\text { berdasarkan } \\
\text { emas }\end{array}$ & $\begin{array}{c}\text { Nilai } \\
\text { berdasarkan } \\
\text { perak }\end{array}$ \\
\hline \multicolumn{2}{|c|}{ Kehilangan nyawa } & $\begin{array}{l}\text { Diat penuh } \\
(100 \%)\end{array}$ & RM778,000.00 & RM240,000.00 \\
\hline \multicolumn{5}{|c|}{ A. Kehilangan anggota tubuh } \\
\hline \multicolumn{5}{|c|}{ (i) Anggota tunggal pada badan } \\
\hline 1. & Hidung & \multirow{5}{*}{ Diat penuh $(100 \%)$} & \multirow{6}{*}{ RM778,000.00 } & \multirow{6}{*}{ RM240,000.00 } \\
\hline 2. & Zakar & & & \\
\hline 3. & Lidah & & & \\
\hline 4. & $\begin{array}{l}\text { Tulang } \\
\text { belakang (al- } \\
\text { sulb) }\end{array}$ & & & \\
\hline 5. & Kulit (al-jald) & & & \\
\hline 6. & Seluruh rambut & $\begin{array}{l}\text { Diat penuh menurut } \\
\text { mazhab Hanafi dan } \\
\text { Hanbali. } \\
\text { Hukūmah al-'adl } \\
\text { menurut mazhab Maliki } \\
\text { dan Syafi'i adalah lebih } \\
\text { rajih. Ini kerana rambut } \\
\text { tidak sama seperti } \\
\text { anggota lain (tangan, } \\
\text { kaki). Ia hanya berfungsi } \\
\text { untuk kecantikan } \\
\text { seseorang sahaja. }\end{array}$ & & \\
\hline \multicolumn{5}{|c|}{ (ii) Anggota berpasangan dua } \\
\hline
\end{tabular}




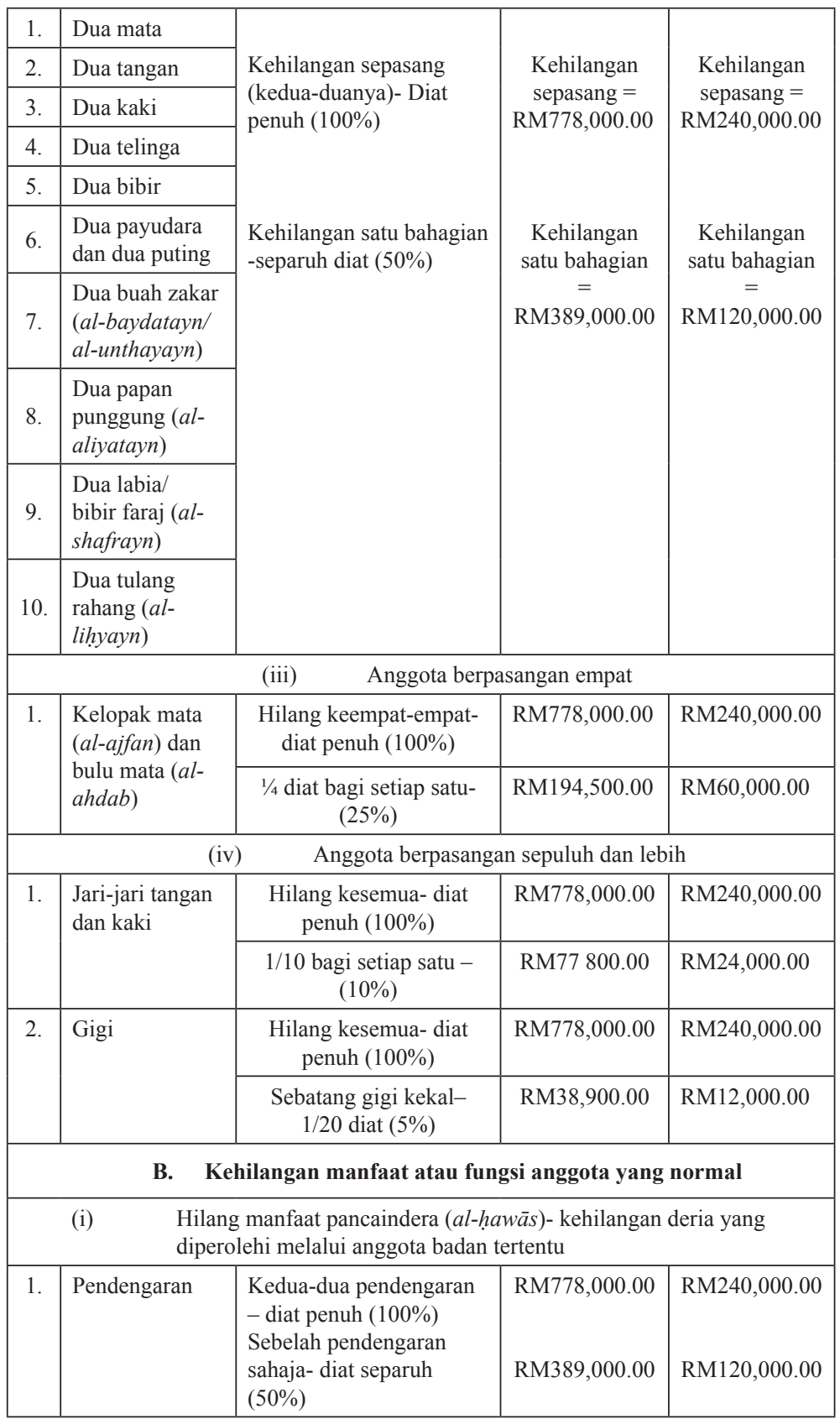


Penetapan Ganti Rugi bagi Pelbagai Kecederaan Diri

Menurut Perundangan Islam

\begin{tabular}{|c|c|c|c|c|}
\hline \multirow[t]{2}{*}{2.} & \multirow[t]{2}{*}{ Penglihatan } & $\begin{array}{l}\text { Kedua-dua penglihatan - } \\
\text { diat penuh }(100 \%)\end{array}$ & RM778,000.00 & RM240,000.00 \\
\hline & & $\begin{array}{l}\text { Sebelah penglihatan - } \\
\text { diat separuh }(50 \%)\end{array}$ & RM389,000.00 & RM120,000.00 \\
\hline \multirow[t]{3}{*}{3.} & \multirow[t]{3}{*}{ Bau } & $\begin{array}{l}\text { Ada beberapa pandangan: } \\
\text { i) Jumhur- diat penuh }\end{array}$ & RM778,000.00 & RM240,000.00 \\
\hline & & $\begin{array}{ll}\text { ii) Jika deria hilang } \\
\text { melalui salah satu } \\
\text { lubang hidung- } \\
\text { separuh diat }\end{array}$ & RM389,000.00 & RM120,000.00 \\
\hline & & $\begin{array}{l}\text { iii) Sebahagian Syafi'i- } \\
\text { hukūmah al- 'adl }\end{array}$ & & \\
\hline \multirow[t]{3}{*}{4.} & \multirow[t]{3}{*}{ Rasa } & $\begin{array}{l}\text { Ada beberapa pandangan: } \\
\text { i) Mazhab Hanafi, } \\
\text { Maliki, Syafie dan } \\
\text { satu riwayat dalam } \\
\text { mazhab Hanbali- } \\
\text { diat penuh }\end{array}$ & RM778,000.00 & RM240,000.00 \\
\hline & & $\begin{array}{l}\text { ii) Imam Ahmad-1/3 } \\
\text { diat }\end{array}$ & RM259,333.33 & RM80,000.00 \\
\hline & & $\begin{array}{l}\text { iii) Imam nawawi- } \\
\text { kalau hilang salah } \\
\text { satu rasa } 1 / 5 \text { diat } \\
\text { (manis, pahit, } \\
\text { masam, masin dan } \\
\text { pedas) }\end{array}$ & RM155 600.00 & RM48,000.00 \\
\hline 5. & $\begin{array}{l}\text { Rasa sentuhan } \\
\text { (al-lams) }\end{array}$ & Diat penuh $(100 \%)$ & RM778,000.00 & RM240,000.00 \\
\hline & $\begin{array}{l}\text { Hil } \\
\text { tert }\end{array}$ & manfaat $a l-m a^{\prime} \bar{a} n \bar{\imath}-\operatorname{manf}$ & lat yang tidak te & letak di anggota \\
\hline
\end{tabular}




\begin{tabular}{|c|c|c|c|c|}
\hline 1. & Hilang akal & \multirow{9}{*}{$\begin{array}{c}\text { Hilang keupayaan } \\
\text { sepenuhnya, diat penuh } \\
(100 \%)\end{array}$} & \multirow{9}{*}{ RM778,000.00 } & \multirow{9}{*}{ RM240,000.00 } \\
\hline 2. & $\begin{array}{l}\text { Kehilangan } \\
\text { kemampuan } \\
\text { untuk berkata- } \\
\text { kata }\end{array}$ & & & \\
\hline 3. & $\begin{array}{l}\text { Kehilangan } \\
\text { suara }\end{array}$ & & & \\
\hline 4. & $\begin{array}{l}\text { Kemampuan } \\
\text { untuk makan } \\
\text { seperti } \\
\text { mengunyah } \\
\text { makanan }\end{array}$ & & & \\
\hline 5. & $\begin{array}{l}\text { Kemampuan } \\
\text { melakukan } \\
\text { hubungan } \\
\text { seksual }\end{array}$ & & & \\
\hline 6. & $\begin{array}{l}\text { Kemampuan } \\
\text { berejakulasi }\end{array}$ & & & \\
\hline 7. & $\begin{array}{l}\text { Kemampuan } \\
\text { untuk } \\
\text { mengandung }\end{array}$ & & & \\
\hline 8. & $\begin{array}{l}\text { Kemampuan } \\
\text { untuk berjalan }\end{array}$ & & & \\
\hline 9. & $\begin{array}{l}\text { Kemampuan } \\
\text { tangan untuk } \\
\text { menggenggam }\end{array}$ & & & \\
\hline \multicolumn{5}{|c|}{ C. Luka dan kecederaan } \\
\hline \multicolumn{5}{|c|}{ Luka dan kecederaan di bahagian muka dan kepala (Shijaj) } \\
\hline \multirow[t]{2}{*}{1.} & \multirow{2}{*}{$\begin{array}{l}\text { Damighah- } \\
\text { luka yang } \\
\text { meretakkan } \\
\text { tengkorak dan } \\
\text { melukakan } \\
\text { membran otak }\end{array}$} & $\begin{array}{l}\text { Terdapat dua pandangan } \\
\text { dalam hal ini iaitu : } \\
\text { • } \quad 1 / 2 \text { diat }\end{array}$ & RM389,000.00 & RM120,000.00 \\
\hline & & $\begin{array}{ll}\text { - } & 1 / 3 \text { diat } \\
& (33.33 \%)\end{array}$ & RM259,333.33 & RM80,000.00 \\
\hline 2. & $\begin{array}{l}\text { Ma'mūmah } \\
\text { - Luka yang } \\
\text { sampai ke } \\
\text { tengkorak }\end{array}$ & $1 / 3$ diat $(33.33 \%)$ & RM259,333.33 & RM80,000.00 \\
\hline 3. & $\begin{array}{l}\text { Munaqqilah } \\
\text { - Luka yang } \\
\text { menampakkan } \\
\text { dan } \\
\text { menghancurkan } \\
\text { tulang }\end{array}$ & $\begin{array}{c}15 \text { ekor unta }=3 / 20 \text { diat } \\
(15 \%)\end{array}$ & RM116,700.00 & RM36,000.00 \\
\hline
\end{tabular}


Penetapan Ganti Rugi bagi Pelbagai Kecederaan Diri

Menurut Perundangan Islam

\begin{tabular}{|c|c|c|c|c|}
\hline 4. & $\begin{array}{l}\text { Hashīmah- } \\
\text { Luka yang } \\
\text { mematahkan } \\
\text { tulang }\end{array}$ & $1 / 10$ diat $(10 \%)$ & RM77,800.00 & RM24,000.00 \\
\hline 5. & $\begin{array}{l}\text { Muwaddihah } \\
\text { - Luka sampai } \\
\text { menampakkan } \\
\text { tulang atau } \\
\text { meretakkannya. }\end{array}$ & $1 / 20$ diat $(5 \%)$ & RM38,900.00 & RM12,000.00 \\
\hline \multicolumn{5}{|c|}{ (ii) Luka dan kecederaan di bahagian lain (Jirah) } \\
\hline 1. & $\begin{array}{l}J a \text { 'ifah - luka } \\
\text { dan kecederaan } \\
\text { yang } \\
\text { menembusi } \\
\text { rongga badan } \\
\text { seperti di dada, } \\
\text { perut, dubur } \\
\text { dan rusuk. }\end{array}$ & $1 / 3 \operatorname{diat}(33.3 \%)$ & RM259,333.33 & RM80,000.00 \\
\hline \multicolumn{5}{|c|}{ D. Keguguran kandungan } \\
\hline 1. & $\begin{array}{l}\text { Bayi telah } \\
\text { dilahirkan } \\
\text { hidup tetapi } \\
\text { meninggal } \\
\text { kemudiannya } \\
\text { kesan daripada } \\
\text { perbuatan salah } \\
\text { yang dilakukan } \\
\text { ke atas ibunya }\end{array}$ & Diat penuh untuk bayi & RM778,000.00 & RM240,000.00 \\
\hline 2. & $\begin{array}{l}\text { Bayi dilahirkan } \\
\text { mati kesan } \\
\text { daripada } \\
\text { perbuatan salah } \\
\text { yang dilakukan } \\
\text { ke atas ibunya }\end{array}$ & $\begin{array}{l}\text { Ghurrah }-5 \text { ekor unta } \\
1 / 20 \text { diat }(5 \%) \\
\text { untuk bayi }\end{array}$ & RM38,900.00 & RM12,000.00 \\
\hline 3. & $\begin{array}{l}\text { Akibat } \\
\text { kecederaan, } \\
\text { ibu meninggal } \\
\text { dunia bersama } \\
\text { kandungan di } \\
\text { dalam perutnya }\end{array}$ & $\begin{array}{l}\text { Tiada diat untuk bayi } \\
\text { kerana kematiannya } \\
\text { berlaku akibat kematian } \\
\text { ibu. Diat penuh untuk ibu }\end{array}$ & RM778,000.00 & RM240,000.00 \\
\hline
\end{tabular}

Jadual 1 di atas menyenaraikan bentuk kehilangan dan kecederaan yang diperuntukkan dengan diat dan arsh. Kadar tersebut bersifat mengikat dan perlu diputuskan oleh para hakim bagi bentuk-bentuk kecederaan yang dinyatakan. Perubahan nilai hanya berlaku pada nilai Ringgit Malaysia sesuai dengan 
perubahan harga emas dan perak semasa. Selain daripada kehilangan dan kecederaan di atas, penilaiannya terpulang kepada para hakim sebagai hukümah al- 'adl.

Daripada jadual di atas juga, dapat dilihat perbezaan kadar diat menggunakan nilai emas dan perak. Kerajaan boleh memilih sandaran nilai yang bersesuaian agar jumlah keseluruhan ganti rugi daripada beberapa diat, arsh dan hukūmah al-'adl yang dikenakan bagi pelbagai kecederaan yang dialami oleh mangsa nanti, tidak terlalu tinggi.

\section{PENETAPAN GANTI RUGI BAGI KECEDERAAN DIRI YANG PELBAGAI}

Terdapat dua asas pelaksanaan sesuatu taklifan yang ditaklifkan ke atas mukallaf iaitu ta'addud dan tadākhul. Secara amnya ta'addud merupakan asas pelaksanaan sesuatu taklifan syarak iaitu setiap sesuatu mesti dikerjakan atau ditunaikan secara berasingan, namun dalam sesetengah keadaan tadākhul menjadi asas pelaksanaan sesuatu hukum. Apabila ia menepati kaedahkaedah yang membolehkan berlakunya sesuatu hukum secara tadākhul.

Daripada nas al-Quran dan hadis yang menetapkan kadar diat dan arsh ini, terbit beberapa kaedah penetapan melalui ijtihad para fuqaha. Ijtihad berlaku dalam beberapa keadaan. Pertama, apabila kecederaan melibatkan beberapa anggota tubuh yang berlainan. Kedua, apabila kehilangan anggota atau manfaatnya dan kecederaan bertindan di bahagian yang berkaitan. Ketiga, kecederaan yang berlaku adalah kecil dan kehilangan anggota tidak berlaku secara total. Bagi kecederaan bentuk yang pertama, kaedah al-ta 'addud digunakan. Manakala bagi kecederaan bentuk kedua, kaedah al-tadākhul diaplikasi dan bentuk kecederaan ketiga ditetapkan kadar ganti rugi berdasarkan kaedah nisbah.

Secara umumnya, diat dan arsh diberikan secara ta 'addud atau berasingan bagi beberapa kecederaan dan hilang keupayaan yang menimpa mangsa. Kadar keseluruhan diat dan arsh yang diperuntukkan bagi seseorang mangsa tidak mempunyai had minimum atau maksimum. Ini kerana penetapan kadarnya bergantung pada bilangan kehilangan dan kecederaan anggota. 
Sekiranya seorang pemandu menyebabkan kematian beberapa orang mangsa, dia bertanggungjawab menjelaskan diat bagi setiap nyawa tersebut. ${ }^{20}$ Jika seorang pemandu menyebabkan beberapa kecederaan ke atas individu tertentu, dia bertanggungjawab ke atas kesemua kecederaan tersebut. ${ }^{21}$ Berdasarkan perbincangan fuqaha, seorang mangsa boleh menerima sehingga 27 diat bagi pelbagai kehilangan anggota dan hilang keupayaan total yang berlaku terhadap anggota tubuhnya. ${ }^{22}$

\section{Konsep al-tadākhul dalam hukuman diat terhadap kecederaan yang pelbagai}

Dalam keadaan tertentu, ganti rugi boleh disatukan iaitu apabila kecederaan dan hilang keupayaan berlaku pada anggota yang sama. Penyatuan ganti rugi ini dibuat berdasarkan kaedah al-tadākhul. Dari segi bahasa, al-tadākhul merupakan perkataan daripada bahasa Arab iaitu تداخل, disebut dengan bacaan huruf $t \bar{a}$, berbaris atas, dan huruf $k h \bar{a}$ ' berbaris depan. Secara etimologinya ia berasal dari kata akar دخل yang membawa erti masuk dan berlawanan dengannya ialah خرخ yang bermaksud keluar. Kalimah dari segi bahasa dibina atas wazan تداخل yang membawa erti saling, ianya memenuhi maksud perkongsian di antara dua perkara dan boleh juga dikatakan saling memasuki. Menurut Ibn Manẓūr23, ungkapan تداخل الأمور memberi erti تشبهـ (menyerupai), atau (memakaikan), atau memasukkan sesuatu ke dalam sesuatu yang lain.

Manakala daripada sudut terminologi, terdapat pelbagai takrifan yang dinyatakan. Menurut al-Suyūṭi, al-tadākhul

$20 \quad$ Sa‘dī Abū Jīb, Mawsū ‘at al-Ijmā' fì al-Fiqh al-Islāmī (Damsyik: Dār al-Fikr, 1999), 1: 437.

21 Muḥammad Aḥmad Sarāj, Damānn al- 'Udwān,446; Sa‘dī Abū Jīb, Mawsū'at al-Ijmā', 1: 437; Najm 'Abd Allah Ibrāhīm al-'Aysāwī, al-Jināyah 'alā al-Ațrāffì al-Fiqh al-Islāmī (Dubai: Dār al-Buhūth li al-Dirāsat al-Islāmiyyah wa Iḥyā' al-Turāth, 2002), 350.

22 Bilangan diat bagi seorang mangsa ini adalah berbeza-beza menurut pandangan fuqaha. Ini kerana pengkelasan anggota dan had anggota yang berbeza di antara mereka. Al-'Aysāwī, al-Jināyah 'alā al-Ațrāf, 350 .

23 Muhammad bin Mukarram Ibn Manẓūr, Lisān al- 'Arab (Beirut: Dār Iṇyā' Turāth al-'Arabī, 1999), 4: 209. 
adalah dihimpunkan dua perkara dari jenis yang sama, dan tidak berbeza tujuannya, dimasukkan satu daripadanya kepada lain yang lebih besar. ${ }^{24}$ Pengertian ini sama dengan pentakrifan Ibn Nujaym dalam kitabnya al-Ashbāh wa al-Nazā' 'ir. ${ }^{25}$ Al-Jurjānī pula mendefinisikan al-tadākhul sebagai memasukkan sesuatu ke dalam sesuatu yang lain tanpa penambahan dari segi isi padu dan kadarnya. ${ }^{26}$ Al-Qarrāfī menghuraikan tadākhul boleh berlaku apabila terdapat beberapa sebab yang sama berlakunya sesuatu perbuatan itu. ${ }^{27}$

Rumusannya, tadākhulboleh difahami sebagaimenghimpunkan dua hukum syarak dengan memadai melakukannya dengan satu perbuatan sahaja iaitu dengan cara memasukkan kepada hukum yang lebih besar dan mendapat pahala ganjaran dan fadilat keduadua amalan tersebut. Dalam erti kata lain, kaedah ini bermaksud mengambil satu hukum daripada dua hukum yang berbeza, bagi dua perkara yang berlaku. ${ }^{28}$ Justeru dalam konteks penetapan diat, nilai ganti rugi bagi dua bentuk kerosakan disatukan dengan memilih salah satu nilai sahaja. ${ }^{29}$ Penyatuan ganti rugi ini dilakukan berpandukan kaedah tadākhul di dalam hukum sebagaimana berikut:

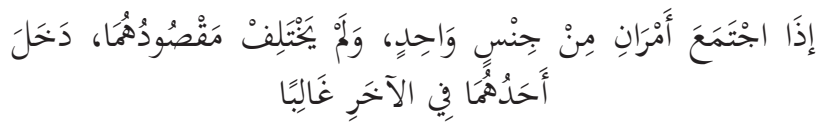

Terjemahan: "Apabila berkumpul dua perkara daripada jenis yang sama dan tidak bertentangan

24 Jalāl al-Dīn 'Abd Raḥman al-Suyūtī, al-Ashbāh wa al-Naẓā'ir (Kāherah: Dār Salam, 2009), 288.

25 Zayn al-Dīn bin Ibrāhīm Ibn Nujaym, al-Ashbāh wa al-Naẓā'ir (Damsyik: Dār Fikr, 2005), 147.

26 'Alī Bin Muhammad Syarīf al-Jurjānī, Kitāb al-Ta 'arīfāt (Bāyrūt: Maktabah Lubnān, 1985), 54.

27 Aḥmad bin Idrīs al-Qarrāfî, al-Furūq (Beirut: Dār Kutub 'Ilmiyyah, 1998), 2: 54.

28 Khālīd bin Sa'ad al-Khashlān, al-Tadākhul bayn al-Ahkām fì al-Fiqh al-Islāmī (Riyad: Dār Ishbiliyyā li al-Nashr wa al-Tawzī‘, 1999), 1: 49.

29 Zakariyyā al-Qudah, "Ijtimā' al-'Uqūbah al-Muqaddarah fī al-Fiqh al-Islāmī," Majallah al-Sharī'ah wa al-Dirāsat al-Islāmiyyah 4, no. 8 (Ogos 1987), 127. 


\section{maksud pensyariatannya, kebiasaannya digabungkan} salah satu daripadanya ke dalam satu lagi. "”30

Kaedah di atas menetapkan bahawa apabila dua perkara bertindan, satu hukum boleh diperuntukkan. Namun, penetapan satu hukum sahaja bagi dua perkara ini boleh berlaku apabila wujud dua syarat. Pertama, kedua-dua perkara mestilah daripada jenis yang sama dan kedua, tujuan pensyariatannya juga sama. Syarat ini dihuraikan lebih lanjut oleh para fuqaha yang menetapkan bahawa persamaan perlu wujud pada bentuk perbuatan, ${ }^{31}$ masa, ${ }^{32}$ tempat, ${ }^{33}$ mangsa $^{34}$ dan pelaku ${ }^{35}$ perbuatan tersebut. Dalam aspek penetapan ganti rugi bagi kes kemalangan jalan raya, penyatuan ganti rugi boleh berlaku apabila kecederaan dan kehilangan manfaat berlaku pada anggota yang sama, diakibatkan oleh pelaku yang sama dalam masa yang sama.

Sekiranya wujud persamaan bagi kesemua aspek tersebut, penyatuan ganti rugi boleh dilakukan dengan mengambil nilai ganti rugi yang lebih tinggi. Dalam hal ini, al-Sarakhsī menetapkan satu diat sahaja bagi luka yang menimpa kepala (muwaddihah) dan kerosakan kulit kepala yang menyebabkan botak kekal. Diat ini adalah bagi kerosakan kulit kepala yang menyebabkan botak kekal. Arsh bagi luka di kepala, ditindankan ke dalam diat tersebut. $^{36}$

$30 \quad$ Lafaz yang sedikit berbeza digunakan oleh Ibn Rajab (al-Qawā id li Ibn Rajab) seperti berikut:

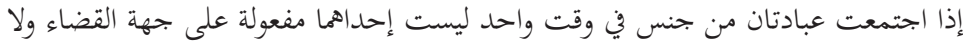

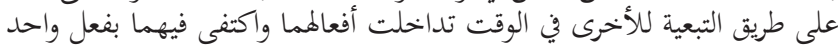

31 Apa yang dimaksudkan dengan persamaan bentuk perbuatan ialah sama ada sengaja, separuh sengaja mahupun tidak sengaja. AlSuyūṭī, al-Ashbāh wa al-Nazāa 'ir (al-Maktabah al-Shāmilah, versi 3.28), 230; al-Khashlān, al-Tadākhul bayn al-Aḥkām, 2: 823.

32 'Abd al-Raḥman bin Șāliḥ, al-Qawā'id wa al-Dawābit al-Fiqhiyyah al-Mutadaminah li al-Taysìr (al-Maktabah al-Shāmilah, versi 3.28), 83; al-Khashlān, al-Tadākhul bayn al-Ahkē̄m, 2: 823.

33 Al-Suyūṭī, al-Ashbāh wa al-Naẓā'ir, 230.

34 Al-Khashlān, al-Tadākhul bayn al-Ahkām, 1: 131.

35 Al-Khashlān, al-Tadākhul bayn al-Aḥkām, 2: 823.

36 Shams al-Dīn al-Sarakhsī, al-Mabsūṭ (Beirut: Dār al-Ma'rifah, t.t), 26: 98 . 
Contoh lain yang dikemukakan oleh al-Sarakhsī, ialah pertindanan hukümah al-'adl bagi tapak tangan yang terpotong ke dalam arsh jari-jemari yang telah ditetapkan syarak. Beliau tidak memutuskan hukūmah al-'adl yang berasingan apabila kebanyakan jari masih wujud pada tapak tangan tersebut. ${ }^{37}$ Secara umum, ini adalah pandangan yang disepakati dalam mazhab Hanafi. Perbezaan pandangan timbul dalam kes seumpama ini, apabila nilai arsh lebih kecil berbanding hukümah al-'adl. Contohnya apabila nilai arsh sebatang jari yang tinggal lebih kecil berbanding hukümah al-'adl tapak tangan yang diputuskan oleh hakim. $^{38}$

Dalam hal ini, pandangan mereka terbahagi kepada dua. Pertama, kadar yang perlu ditetapkan adalah berdasarkan kadar arsh yang telah ditetapkan syarak walaupun kadar arsh tersebut adalah kecil..$^{39}$ Kedua, kadar yang perlu ditetapkan ialah kadar yang lebih banyak walaupun melalui hukümah al-'adl, bukan

37 Al-Sarakhsī, al-Mabsūț, 26: 82.

38 Al-Sarakhsī, al-Mabsūt, 26: 82 - 83.

39 Dalam hal ini, Abu Hanifah kekal dengan pandangan bahawa pertindihan dilakukan dengan memasukkan nilai anggota yang tidak ditetapkan kadar ganti ruginya ke dalam ganti rugi anggota yang ditetapkan kadarnya oleh syarak. Ini bermakna hukümah al'adl bagi tapak tangan ditindankan ke dalam arsh jari dan penetapan remedi dibuat dengan mengambil nilai arsh dua atau sebatang jari yang tinggal. Beliau mengemukakan hujah bahawa arsh jari adalah sabit daripada nas manakala hukūmah al-'adl bagi tapak tangan pula sabit daripada keputusan atau pandangan hakim. Justeru, nilai yang diperuntukkan oleh nas lebih patut diutamakan walaupun mungkin kadarnya kurang daripada hukūmah al- 'adl yang mungkin ditetapkan oleh hakim. Ini kerana beliau berpendapat pandangan atau ijtihad (al-ra'y) tidak boleh bersalahan dengan nas. Ketegasan Abu Hanifah dalam berpegang pada prinsip ini jelas apabila beliau menetapkan bahawa ganti rugi bagi tapak tangan tetap perlu ditindakan ke dalam arsh walaupun hanya tinggal satu ruas pada sebatang jari (al-mafșal) sahaja yang nilai arshnya hanyalah satu pertiga daripada arsh sebatang jari. Al-Sarakhsī, al-Mabsūț, 26: 83 dan 98. 
kadar $\operatorname{arsh}^{40}$ Dalam hal ini, penulis bersetuju dengan pandangan umum bahawa nilai yang lebih tinggi diambil sebagai ganti rugi. Ini lebih menepati maslahah kepada mangsa.

Bagi menentukan sama ada pertindanan kehilangan manfaat dan kecederaan anggota berlaku, para sarjana menyimpulkan beberapa panduan. Pertama, pertindanan berlaku apabila manfaat anggota hilang bersama dengan anggota. ${ }^{41}$ Manfaat pertuturan dan deria rasa contohnya, hilang apabila lidah mangsa terpotong. Dalam kes ini, mangsa hanya diberikan satu diat sahaja iaitu bagi kehilangan lidah bersama manfaatnya. ${ }^{42}$ Kedua, pertindanan tidak berlaku jika manfaat anggota hilang, sedangkan anggota pula kekal dalam keadaan baik. Dalam keadaan ini, ganti rugi diberikan secara berasingan. Sebagai contoh, lidah mangsa kekal baik, tetapi deria rasa dan pertuturannya hilang. ${ }^{43}$

Masalah yang lebih kompleks dan mengundang banyak perselisihan seperti kecederaan kepala yang menyebabkan kehilangan pendengaran, penglihatan dan pertuturan, mahupun

40 Abu Yusuf dan Muhammad pula sebaliknya memilih metod umum bagi kaedah al-tadākhul dalam penetapan ganti rugi iaitu menggabungkan nilai yang sedikit ke dalam nilai yang lebih besar dalam keadaan yang wujud hanya sebatang atau dua jari sahaja. Mereka berpandangan ganti rugi yang patut diberikan ialah hukūmah al-'adl yang mewakili tapak tangan apabila nilainya lebih besar nilainya berbanding arsh jari yang tinggal. Mereka mengibaratkan keadaan kehilangan sebahagian besar jari seperti kehilangan keseluruhannya kerana manfaat genggaman tidak lagi boleh dijalankan oleh sebahagian kecil jari yang tinggal. Oleh kerana itu, ganti rugi yang ditetapkan bagi keadaan ini juga disamakan dengan keadaan terpotongnya tapak tangan yang tidak mempunyai jari padanya iaitu hukūmah al- 'adl. Ibid, 26: 82.

41 Al-Aysāwī, al-Jināyah 'alā al-Ațrā $f, 351$.

42 Al-Khashlān, al-Tadākhul bayn al-Ahkām, 2: 825.

43 Al-Khashlān, al-Tadākhul bayn al-Aḥkām, 2: 825. 
manfaat dalam bentuk al-ma'āni yang lain ${ }^{44}$ seperti akal, penentuannya boleh dirujuk kepada pakar. ${ }^{45}$ Khidmat pakar pernah digunakan oleh Saidina Abu Bakar r.a dalam penentuan bentuk pembalasan yang sesuai dikenakan dalam satu kes yang melibatkan kehilangan telinga mangsa. ${ }^{46}$

Dalam perbincangan fuqaha, berlaku perselisihan dalam menetapkan ganti rugi bagi kecederaan kepala yang menyebabkan kehilangan pendengaran, penglihatan dan pertuturan. Al-Sarakhsī contohnya, menetapkan ganti rugi secara berasingan iaitu tiga diat bagi kehilangan manfaat-manfaat tersebut beserta arsh luka. Walau bagaimanapun, Abu Yusuf pula berpendapat bahawa arsh luka digabungkan dengan diat kehilangan manfaat pendengaran dan pertuturan manakala kehilangan manfaat penglihatan pula diberikan diat yang berasingan. Ini bermakna mangsa perlu diberikan dua diat.

$44 \quad A l-M a ' \bar{a} n \bar{\imath}$ ialah manfaat anggota selain daripada pancaindera (alhawās terbahagi kepada lima iaitu deria rasa, deria bau, deria dengar, deria lihat dan deria sentuh). Al-Ma 'ānī antaranya ialah akal, manfaat pertuturan atau kemampuan bercakap, manfaat suara, manfaat makan (mengunyah), manfaat jimak, manfaat ejakulasi (الإمناء), kemampuan mengandung dan melahirkan anak, kemampuan menggenggam tangan (البطش), kemampuan berjalan, kemampuan pada batang leher untuk melakukan gerakan seperti menanduk (الإحبال). Al-Aysāwī, alJināyah 'alā al-Atrā̄f, 306.

45 Hasil siasatan ini merupakan hujah yang lebih absah dan boleh dipercayai berbanding dakwaan mangsa sendiri. Ia juga mengatasi hujah-hujah aqli seperti yang dikemukakan oleh para fuqaha bahkan boleh mengatasi ijtihad para sahabat yang dilakukan sesuai dengan pengetahuan dan perkembangan ilmu di zaman mereka. Bahkan pandangan pakar dianggap sebagai bonus dalam prosedur siasatan di dalam Islam bagi mengumpul bukti-bukti jenayah. Muhammad Rashīd al-'Umar, Ușūl al-Tahqūq al-Jinā'̄̄ fì al-Sharī'ah alIslāmiyyah Dirāsah Fiqhiyyah Muqāranah (Damsyik: Dār alNawādir, 2008), 156.

46 Dalam satu kejadian yang berlaku di zaman Abu Bakar r.a, seorang budak telah dipotong telinganya. Dalam memutuskan hukuman yang sesuai kepada pelakunya sama ada boleh diqisas atau memadai dengan diat, Saidina Abu Bakar r.a merujuk kepada seorang yang pakar dalam hal-hal kecederaan. Muhammad Rashīd al-'Umar, Uṣū al-Tahqūq al-Jinā' '̄, 161. 
Perbezaan pandangan ini timbul disebabkan perbezaan pandangan mereka dalam menentukan kedudukan manfaatmanfaat tersebut. Abu Yusuf berpandangan manfaat penglihatan adalah jelas dan zahir kedudukannya secara hukum dan hakikat sedangkan manfaat pendengaran dan pertuturan pula bersifat batin atau tidak kelihatan. Justeru itu, diat bagi deria penglihatan yang zahir kedudukannya diberikan secara berasingan sedangkan manfaat pendengaran dan pertuturan yang sama-sama bersifat batin kedudukannya digabungkan dengan luka kepala. Penggabungan dua manfaat yang batin ini dengan arsh luka kepala dilakukan sebagaimana digabungkan diat kehilangan akal yang bersifat batin dengan arsh bagi luka di kepala.

Pandangan ini berbeza dengan pandangan al-Sarakhsī yang menetapkan ganti rugi secara berasingan. Ini kerana menurut mereka kedudukan deria dengar bukan terletak di kepala tempat kecederaan berlaku. Begitu juga dengan penglihatan dan pertuturan. Justeru, diat kesemua manfaat anggota yang berlainan kedudukannya itu perlu diberikan secara berasingan. Al-Sarakhsī menyokong pandangan beliau dengan penghakiman Saidina Umar yang menetapkan empat diat secara berasingan bagi kehilangan akal, penglihatan, pertuturan dan manfaat seksual akibat kecederaan kepala yang menimpa seorang lelaki seperti mana yang telah dinyatakan sebelum ini. ${ }^{47}$

Bagi kecederaan kepala yang melibatkan kehilangan akal pula, perselisihan pandangan oleh fuqaha terbahagi kepada tiga pandangan. Pertama, ganti rugi bagi kecederaan kepala dan kehilangan akal diberikan secara berasingan. Ini kerana akal adalah satu manfaat yang tidak mempunyai tempat atau anggota yang khusus, maka tempat kecederaan kepala tersebut tidak sama dengan tempat kehilangan akal. Pandangan kedua, arsh kecederaan disatukan bersama diat kehilangan akal. Mereka berhujah bahawa kehilangan akal telah menghilangkan manfaat keseluruhan anggota tubuh atau dalam erti kata lain, keseluruhan anggota tidak bermanfaat tanpa kewujudan akal. Akal manusia juga tidak mempunyai tempat yang khusus di badan, sepertimana kedudukan ruh kepada jasad. Pandangan ketiga pula menetapkan bahawa jika kecederaan kepala tersebut mencapai kadar satu diat,

47 Al-Sarakhsī, al-Mabsūṭ, 26: 99. 
maka ia tidak boleh ditindakan bersama diat kehilangan akal. Jika kadarnya lebih rendah, maka menurut satu pandangan, keduadua ganti rugi hendaklah disatukan. ${ }^{48}$ Dalam hal ini, penyelesaian dapat dibuat dengan merujuk kepada keterangan pakar. Dengan bantuan teknologi semasa, pengkelasan kecederaan kepada satu anggota yang sama atau dua anggota yang berlainan dapat ditentukan dengan lebih tepat.

\section{Penetapan Kadar Ganti Rugi Berdasarkan Nisbah}

Bagi kecederaan kecil anggota, kadar ganti ruginya ditetapkan oleh para fuqaha menggunakan kaedah nisbah. Kadar ganti rugi ditetapkan berdasarkan nisbah kecederaan yang berlaku terhadap anggota penuh yang ditetapkan nilai diat atau arshnya. Kaedah ini boleh disandarkan kepada hadith Nabi SAW. Antaranya berkenaan penetapan setengah diat bagi kehilangan salah satu daripada anggota berpasangan dua ${ }^{49}$ dan satu persepuluh diat bagi anggota berpasangan sepuluh. ${ }^{50}$ Daripada hadith Nabi SAW berkenaan, para fuqaha menetapkan setengah diat bagi kehilangan sebelah payudara dan puting susu wanita, tulang rahang, bibir kemaluan dan papan punggung. ${ }^{51}$ Satu perempat diat pula ditetapkan bagi anggota yang berpasangan empat seperti kelopak mata dan bulu

48 Al-Sarakhsī, al-Mabsūț, 26: 99; Al-'Aysāwī, al-Jināyah 'alā alAtrā̃f, 335-337.

49 Anggota berpasangan dua yang ditetapkan kadarnya melalui hadis secara jelas ialah tangan, kaki, mata, bibir, telinga dan dua buah zakar. Lihat Sunan Ab̄̄ Dāud, Kitāb al-Diyyāt, Bāb Diyyāt al-A'ḍā', hadith no. 4564; Sunan al-Nasā '̄, Kitāb al-Qasāmah wa al-Qawad wa al-Diyyāt, Dhikru Hadīth 'Amru bin Ḥazm fī al-'Uqūl wa Ikhtilāf al-Nāqilīn lahu, hadith no. 4657 dan 4658.

50 Anggota berpasangan sepuluh ialah jari-jari tangan dan kaki. Lihat Sunan Abì Dāud, Kitāb al-Diyyāt, Bāb Diyyāt al-A 'ḍā', hadith no. 4556, 4557, 4562 dan 4564; Jāmi ' al-Tirmìdhì, Abwāb al-Diyyāt, Bāb mā Jā'a fĩ Diyyāt al-Așābi', hadith no. 1391; Sunan al-Nasā' '̄, Kitāb al-Qasāmah wa al-Qawad wa al-Diyyāt, Bāb 'Aql al-Așābi', hadith no. 4848, 4860 dan 4861; Sunan Ibn Mājah, Abwāb al-Diyyāt, Bāb Diyyāt al-Așābi‘, hadith no. 2653.

51 Al-'Aysāwī, al-Jināyah 'alā al-Ațrāf, 272-284. 
mata. ${ }^{52}$ Para fuqaha juga berijtihad menetapkan kadar satu pertiga arsh jari bagi setiap ruas pada sebatang jari (الأنملة).53

Kaedah ini juga diaplikasikan dalam penetapan kadar arsh bagi kecederaan kecil anggota dan pancaindera. Ini juga bersandarkan kepada hadith Nabi SAW yang menetapkan satu pertiga diat bagi kecederaan mata yang sedia buta, ${ }^{54}$ satu pertiga diat bagi tangan yang sudah sedia lumpuh ketika dipotong ${ }^{55}$ dan satu pertiga diat bagi gigi yang sudah sedia hitam ketika dicabut. ${ }^{56}$

Walau bagaimanapun, bagi kes yang lebih kompleks, berlaku perselisihan pendapat di kalangan fuqaha. Contohnya, terdapat empat pandangan dalam menetapkan arsh kehilangan sebahagian manfaat pertuturan. Pertama, penetapan arsh dibuat berdasarkan nisbah bilangan huruf yang tidak boleh dituturkan oleh mangsa, daripada 28 huruf arab. ${ }^{57}$ Pandangan kedua pula, penisbahan dibuat terhadap 16 atau 18 huruf yang biasa dituturkan oleh percakapan (al-hurūf al-muta 'alliqah bi al-lisān). ${ }^{58}$ Ketiga, nisbah

52 Al-Sarakhs̄î, al-Mabsūț, 26: 70; Al-'Aysāwī, al-Jināyah 'alā alAțā́f, 284-287.

53 Al-Sarakhsī, al-Mabsūt, 26: 75; Al-'Aysāwī, al-Jināyah 'alā alAțrāf, 289-290.

54 Sunan Abì Dāud, Kitāb al-Diyyāt, Bāb Diyyāt al-A 'ḍā', hadith no. 4567; Sunan al-Nasā̄ $\bar{\imath}$, Kitāb al-Qasāmah wa al-Qawad wa alDiyyāt, Bāb al-'Ayn al-'Awrā’ al-Saddah li Makānihā Idhā Țumisat, hadith no. 4844.

55 Sunan al-Nasā '̄ , Kitāb al-Qasāmah wa al-Qawad wa al-Diyyāt, Bāb al-‘Ayn al-'Awrā' al-Saddah li Makānihā Idhā Ṭumisat, hadith no. 4844.

56 Ibid.

57 Ini merupakan salah satu daripada tiga pandangan di dalam mazhab hanafi, salah satu daripada dua pandangan dalam mazhab Syafie dan salah satu daripada dua pandangan dalam mazhab Hanbali. Rujuk perbahasan di dalam al-'Aysāwī, al-Jināyah 'alā al-Ațrāf, 339-340; Al-Nawawī, al-Minhāj (al-Maktabah al-Shamilah versi 3.28), 1: 411.

58 Pembahagian dibuat berdasarkan 16 huruf ini merupakan salah satu pandangan dalam mazhab Hanafi manakala pembahagian berdasarkan 18 huruf pula adalah salah satu pandangan dalam mazhab Syafie dan Hanbali. Rujuk perbahasan di dalam al-'Aysāwī, al-Jināyah 'alā al-Ațrāf, 339-342. 
kehilangannya perlu merujuk kepada ijtihad pakar. ${ }^{59}$ Keempat, diyat penuh diberikan jika mangsa tidak mampu menuturkan kebanyakan huruf, manakala hukūmah al-'adl pula diberikan jika sedikit. ${ }^{60}$

Kaedah nisbah diaplikasikan oleh para fuqaha bagi kes yang dapat ditentukan kadarnya. Contoh lain ialah seperti setengah diat bagi kehilangan deria bau daripada salah satu lubang hidung dan satu perlima diat bagi kehilangan salah satu daripada lima rasa pada lidah manusia. ${ }^{61}$ Jika kadar kecederaan dan hilang keupayaan anggota tidak dapat ditentukan, barulah hukūmah al-'adl diperuntukkan dan kadarnya dipulangkan kepada pemerintah. ${ }^{62}$

\section{PENUTUP}

Daripada perbincangan, dapat dirumuskan bahawa Syariat Islam mengangkat tinggi nilai-nilai keadilan melalui sistem perundangannya. Setiap sesuatu yang dikurniakan oleh Allah SWT kepada manusia mempunyai hak yang dilindungi syarak. Dalam konteks kehilangan nyawa dan kecederaan diri, diat diperuntukkan bagi membela mangsa atau waris mangsa dari sudut harta. Sungguh pun begitu, pelaku salah tidak dizalimi dengan penetapan ganti rugi yang melampaui hadnya. Hal ini dibuktikan dengan wujudnya elemen tadākhul dalam pelaksanaan hukuman diat apabila kecederaan yang pelbagai dan kehilangan fungsi tubuh berlaku pada satu anggota yang sama. Begitu juga dengan kecederaan sebahagian anggota tubuh yang diperuntukkan dengan nilai ganti rugi atau arsh yang mengikut nisbah atau berkadaran dengan kecederaan yang dialami. Dalam hal ini, kaedah umum bagi ganti rugi iaitu al-ta'addud yang bermaksud ganti rugi diperuntukkan secara berasingan bagi

59 Jika pakar berpendapat bahawa kehilangan pertuturan adalah sebanyak satu perempat atau satu pertiga, maka remedi akan diberikan sebanyak itu dengan menisbahkannya kepada nilai diat. Ini merupakan pandangan Mazhab Maliki. Ibid, 340

60 Ini merupakan salah satu pandangan dalam mazhab Hanafi. Ibid, 340.

$61 \quad$ Ibid, 324 dan 326; Al-Nawawī, al-Minhāj, 1: 412.

62 Al-Nawawī, al-Minhājj, 1: 411; al-'Aysāwī, al-Jināyah 'alā al-Aṭā̄f, 310-311, 318, 326, 330 dan 334. 
setiap kecederaan yang dialami tidak diaplikasikan. Berdasarkan perbincangan, penetapan kadar ganti rugi berdasarkan kaedahkaedah ini mempunyai sandaran daripada hadith Nabi SAW dan dibincangkan secara terperinci oleh para fuqaha. Dalam konteks semasa, ia sudah memadai sebagai panduan asas bagi pelaksanaan diat dalam konteks semasa. Walaupun sandaran hadith Nabi SAW dan perbincangan fuqaha dalam hal ini mungkin tidak menyentuh semua bentuk kecederaan, persoalan berbentuk ijtihadi ini boleh dirujuk kepada pakar yang berkenaan dan boleh ditentukan melalui perkembangan teknologi semasa terutamanya apabila melibatkan kecederaan yang kompleks. Justeru, jelas bahawa diat secara khususnya dan undang-undang Islam secara amnya sentiasa sesuai dan boleh dilaksanakan sepanjang zaman.

\section{RUJUKAN}

'Abd al-Raḥman bin Șāliḥ. Al-Qawā'id wa al-Ḍawābiṭ alFiqhiyyah al-Mutadaminah li al-Taysìr. Al-Maktabah alShamilah, versi 3.28.

Al-Aysāwī, Najm 'Abd Allah Ibrāhīm. Al-Jināyah 'alā al-Ațrāf fì al-Fiqh al-Islāmī. Dubai: Dār al-Buhūth li al-Dirāsat alIslāmiyyah wa Iḥyā' al-Turāth, 2002.

Al-Jurjān̄̄, 'Alī bin Muhammad Sharīf. Kitāb al-Ta 'arīfāt. Beirut: Maktabah Lubnān, 1985.

Al-Khashlān, Khālid bin Sa'ad. Al-Tadākhul bayn al-Aḥkām fì al-Fiqh al-Islāmī. Riyad: Dār Ishbiliyyā li al-Nashr wa alTawzī', 1999.

Muḥammad Aḥmad Sarāj. Damān al- 'Udwān fì al-Fiqh al-Islāmī Dirāsah Fiqhiyyah Muqāranah bi Ahkām al-Mas'ūliyyah al-Taqsīriyyah fì al-Qānūn. Kaherah: Dār al-Thaqāfah li alNashr wa al-Tawzī‘, 1990.

Muhammad bin Mukarram Ibn Manzūur. Lisān al-'Arab. Beirut: Dār Iḥyā’ Turāth al-‘Arabī, 1999.

Muḥammad Rashīd al-'Umar. Ușūl al-Taḥqīq al-Jinā'̀ fì alSharī'ah al-Islāmiyyah Dirāsah Fiqhiyyah Muqāranah. 
Damsyik: Dār al-Nawādir, 2008.

Al-Nawawī, Muḥy al-Dīn. Al-Minhāj: fì Sharh Șaḥiḥ Muslim bin al-Hajjāj. 'Ummān: Bayt al-Afkār al-Dawliyyah, 2010.

Portal rasmi Kelantan Golden Trade. Capaian pada 1 November 2018. https://kgt.com.my/shop/index.php?route=product/ product\&product_id $=58 \&$ search $=$ dinar.

Portal rasmi Kelantan Golden Trade. Capaian pada 1 November 2019. https://kgt.com.my/shop/index.php?route=product/ search\&search=dirham

Al-Qarrāfī, Ahmad bin Idrīs. Al-Furūq. Beirut: Dār Kutub 'Ilmiyyah, 1998.

Sa 'dī Abū Jīb. Mawsū'at al-Ijmā' fì al-Fiqh al-Islāmī. Damsyik: Dār al-Fikr, 1999.

Al-Sarakhsī, Syams al-Dīn. Al-Mabsūṭt. Beirut: Dār al-Ma'rifah, t.t.

Siti Zubaidah Ismail, "Kecuaian dan Ganti rugi terhadap Kecederaan Fizikal Menurut Undang-undang Tort Islam". Tesis kedoktoran, Akademi Pengajian Islam Universiti Malaya, 2005.

Al-Suyūtī, Jalāl al-Dīn 'Abd Raḥman. Al-Ashbāh wa al-Naẓā'ir. Kaherah: Dār Salam, 2009.

Zakariyyā al-Qudah. "Ijtimā' al-'Uqūbah al-Muqaddarah fī alFiqh al-Islāmī." Majallah al-Sharīah wa al-Dirāsat alIslāmiyyah 4, no. 8 (Ogos 1987).

Zayn al-Dīn Abd Raḥman bin Aḥmad Ibn Rajab. Taqrīr alQawā' '̀d wa Tahrīir al-Fawā'id. Dār Ibn 'Affān, t:t.

Zayn al-Dīn bin Ibrāhīm Ibn Nujaym. Al-Ashbāh wa al-Naẓā'ir . Damsyik: Dār Fikr, 2005.

Al-Zuhaylī, Muḥammad. Nazariyyat al-Ḍamān aw Ahkām alMas'ūliyyah al-Madaniyyah wa al-Jinā'iyyah fì al-Fiqh al-Islāmī Dirāsah Muqāranah. Damsyik: Dār al-Fikr, 1998. 